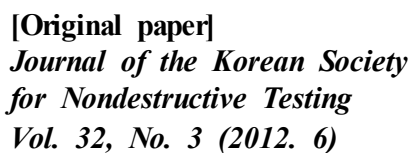

\title{
Infrared Thermography Quantitative Diagnosis in Vibration Mode of Rotational Mechanics
}

\author{
Jin Ju Seo*, Nam Ryoung Choi*, Won Tae Kim**† and Dong Pyo Hong*
}

\begin{abstract}
In the industrial field, real-time monitoring system like a fault early detection is very important. For this, the infrared thermography technique as a new diagnosis method is proposed. This study is focused on the damage detection and temperature characteristic analysis of ball bearing using the non-destructive infrared thermography method. In this paper, thermal image and temperature data were measured by a Cedip Silver $450 \mathrm{M}$ infrared camera. Based on the results, the temperature characteristics under the conditions of normal, loss lubrication, damage, dynamic loading, and damage under loading were analyzed. It was confirmed that the infrared technique is very useful for the detection of the bearing damage.
\end{abstract}

Keywords: Infrared Thermography, Damage Detection, Ball Bearing, Real-Time Monitoring, Dynamic Loading

\section{Introduction}

Ball bearing is a power transmission element widely used in various types of industrial rotating machinery such as motors, gas turbines, and pumps. It has many advantages like ease of lubrication and low wear during operation [1]. But in case of rotating machinery, resonance and the damage of bearing by fatigue can cause the largest industrial disasters or economic loss. Therefore, the borne damage and state of the machine have to be known through regular fault diagnosis in advance and an alternative has to be established. In general, the diagnostic system is a way to predict abnormalities of bearing components by analyzing the magnitude and frequency of vibration according to local defects in ball bearings [2]. However, inspection system that requires direct contact of devices or instruments with the subject significantly reduces operation time [3].
Non-contact, non-destructive inspection techniques that utilize the infrared technology are useful for rapid inspection and real-time monitoring and are cost-effective and harmless to humans [4]. Such a method uses an infrared camera that takes photograph of the infrared ray emitted to an object. The difference in temperatures shows the specific pattern between normal and damaged parts.

In this paper, study for damage detection and temperature characteristics of ball bearing under various conditions using infrared thermography method was carried out.

\section{Experimental Configuration}

An experimental work was performed by using B6304 as the test piece. B6 series are widely used in the insulation deep groove ball bearing. Fig. 1 shows the schematic dimensions of bearing used in this experiment. The bearing

[Received: May 8, 2012. Revised: June 5, 2012. Accepted: June 8, 2012] *Department of Precision Mechanical Engineering Chonbuk National University, Cheonju, Jeonbuk 561-756, Korea, **Division of Mechanical and Automotive Engineering Kongju National University, Cheonan, Chungnam 331-717, Korea †Corresponding Author: kwt@kongju.ac.kr 


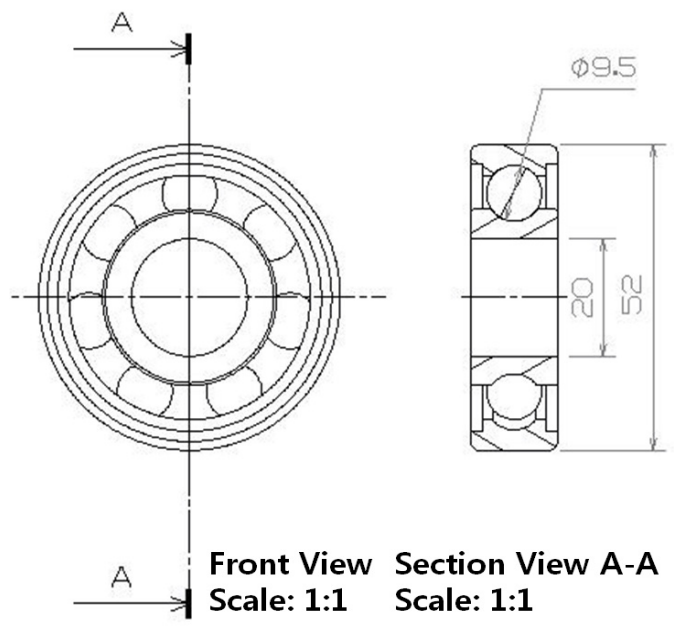

Fig. 1 Schematic dimensions of bearing

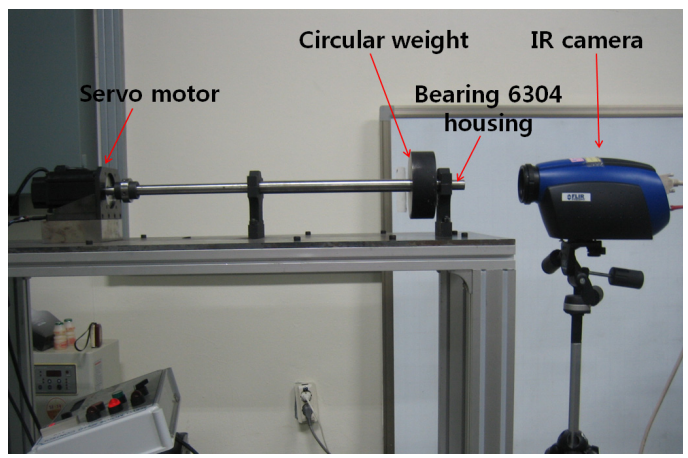

Fig. 2 Experimental configuration using infrared camera

B6804 and housing were installed between a power and a measuring bearing (B6304) for simple support. Fig. 2 shows the experimental configuration using infrared camera. A circular weight of $5 \mathrm{~kg}$ was mounted to the axis in order to carry out a dynamic loading condition test. The outer ring of bearing was instrumented with a surface damage (scratch) of $0.99 \mu \mathrm{m}$ in order to simulate a damaged test piece. The roughness of normal bearing is smaller than $0.2 \mu \mathrm{m}$.

In this paper, the temperature characteristics according to the five conditions of normal, loss lubrication, damaged, dynamic loading, damaged under loading were analyzed. By using the APM-SC08ADK servo motor of $1 \mathrm{HP}$ on $800 \mathrm{~W}$, the experiment was performed in 1,000 ,
Table 1 The main specifications of infrared camera

\begin{tabular}{|c|c|}
\hline Sensor material & InSb \\
\hline Pixel resolution @ Pitch & $320 \times 240$ pixel @ 30 $\mu \mathrm{m}$ \\
\hline Spectrum response & $2.5-5 \mu \mathrm{m}$ \\
\hline Full-frame speed & Max 380 Hz \\
\hline NETD & $<20 \mathrm{mK}$ \\
\hline Filter wheel & 1 " filter $1 \mathrm{~mm}$ thickness 4 slot \\
\hline Digital output & GigE / CAMLINK \\
\hline
\end{tabular}

2,000, 3,000 rpm (revolutions per minute), respectively. The model of the infrared camera used this experiment is the Silver $450 \mathrm{M}$ of Cedip Corp. (France) and Table 1 is the main specifications of the camera.

\section{Result and Consideration}

By using the infrared camera, an experiment measured 20 frames per second for 40 minutes. The device was set up such that $1,000,2,000$, 3,000 rpm can be reached within 3 seconds after starting. The change of the temperature characteristics of the bearing was observed on a real time basis. The data was calculated from the connection of intrados and outer ring and the ball of the bearing in which the generation of heat is most serious [5]. The time stage curve of temperature was made by using data from room temperature until maximum temperature of bearing. Fig. 3, 5, 7, 9, 11 are time stage curve until maximum temperature according to the five conditions of normal, loss lubrication, damaged, dynamic loading, damaged under loading. Fig. 4, $6,8,10,12$ show the respective thermal image under the five conditions in $3,000 \mathrm{rpm}$.

In the graph, first, the maximum temperature values by the remaining four-condition are higher than that of the normal lubrication condition. Particularly, in case of damaged, dynamic loading and damaged under loading conditions, graphs show very sharp temperature 


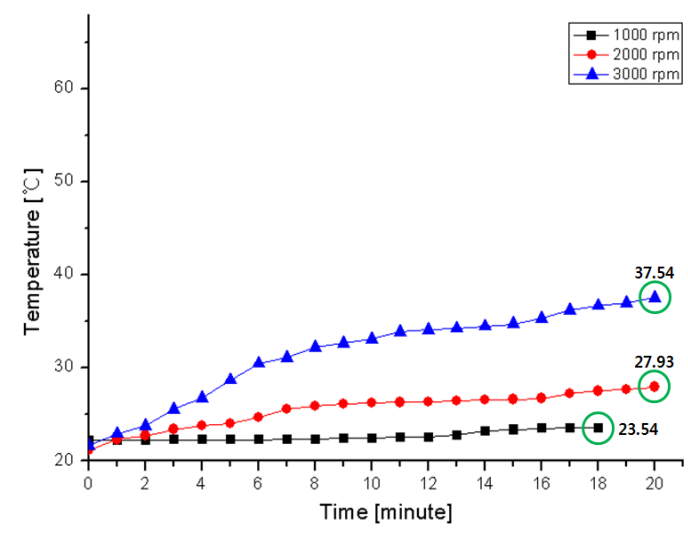

Fig. 3 Normal condition of B6304

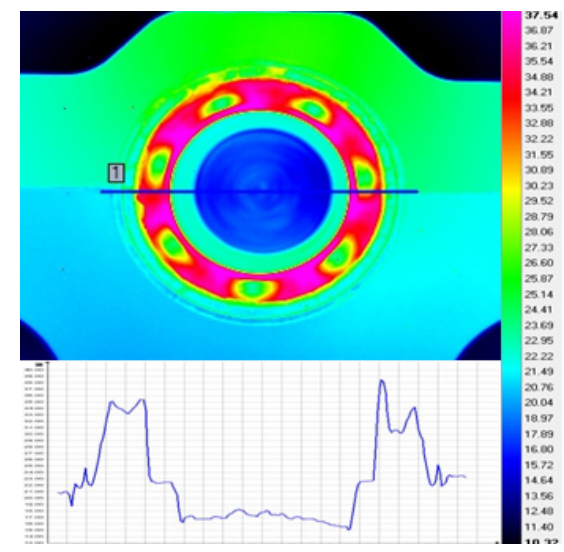

Fig. 4 Thermal image of normal condition in 3,000 rpm

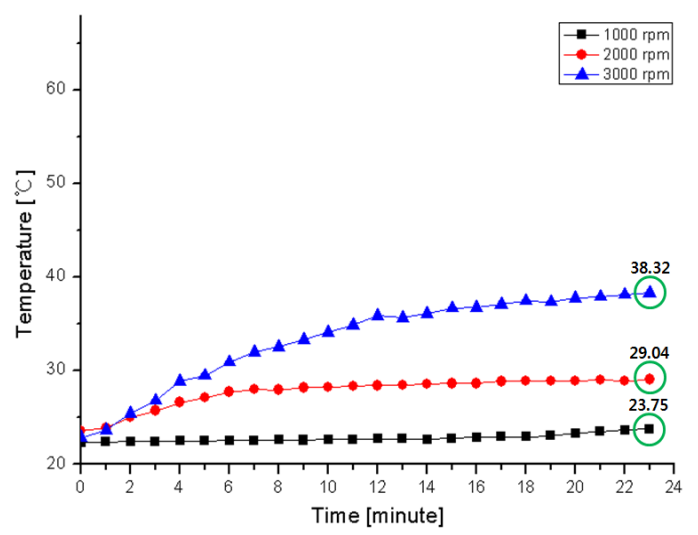

Fig. 5 Loss lubrication condition of B6304

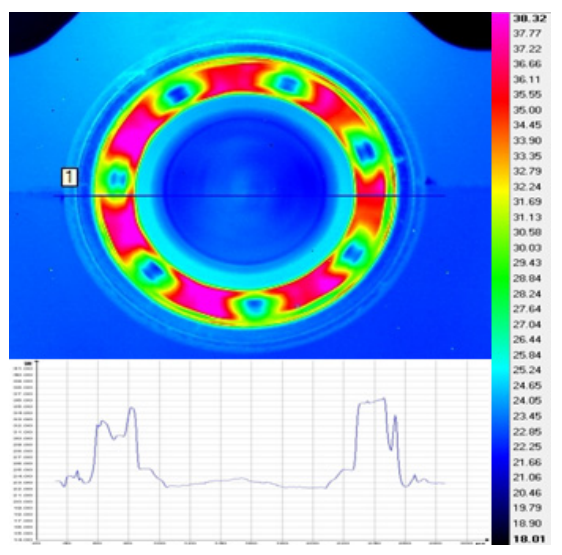

Fig. 6 Thermal image of loss lubrication condition in $3,000 \mathrm{rpm}$

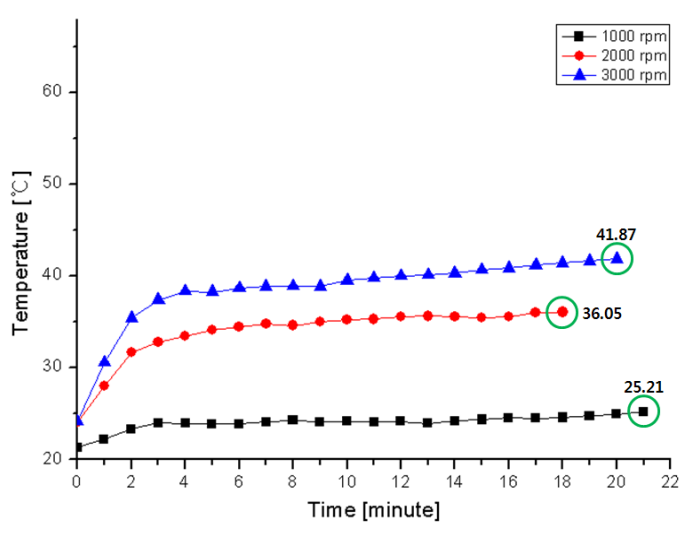

Fig. 7 Damaged condition of B6304

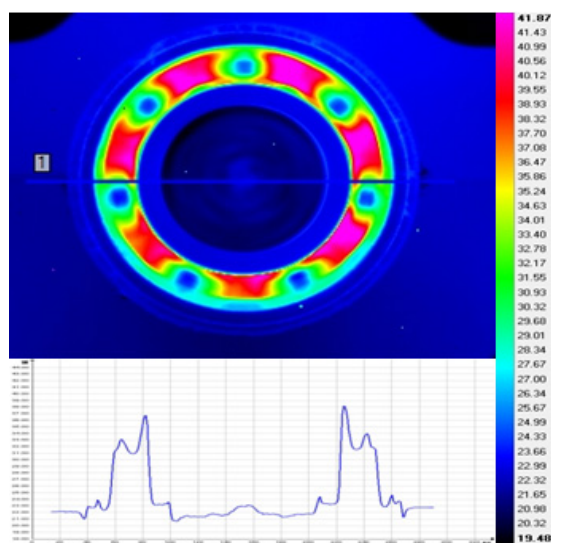

Fig. 8 Thermal image of damaged condition in $3,000 \mathrm{rpm}$ 


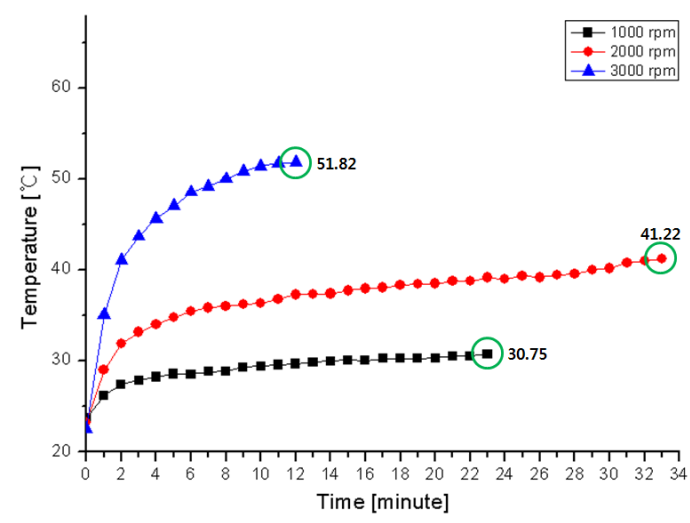

Fig. 9 Dynamic loading condition of B6304

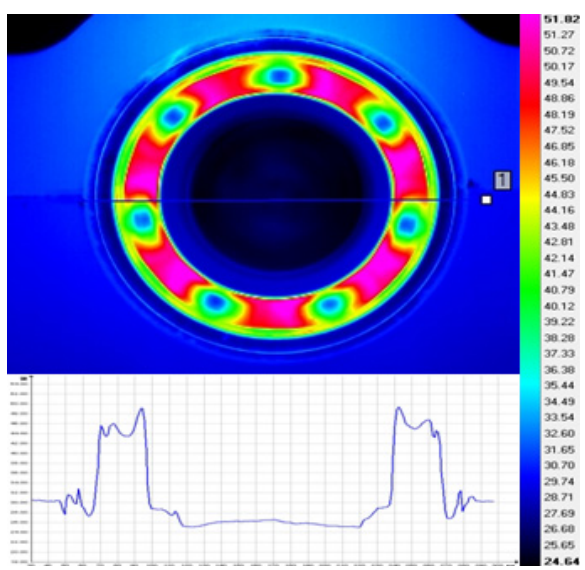

Fig. 10 Thermal image of dynamic loading condition in $3,000 \mathrm{rpm}$

gradients within about 3 minutes against normal and loss lubrication conditions.

Comparing the value of the maximum temperature in each state, the temperature of damaged bearing based on the normal condition value increased by about $7 \%, 29 \%, 12 \%$ in $1,000,2,000,3,000 \mathrm{rpm}$. The temperature of damaged bearing under loading condition remarkably increased at about 39\%, 95\% 76\% in $1,000,2,000,3,000 \mathrm{rpm}$.

Comparing the value of the maximum temperature based on the $1,000 \mathrm{rpm}$ according to rpm, the temperature of normal bearing increased by about $19 \%, 60 \%$ in 2,000 ,

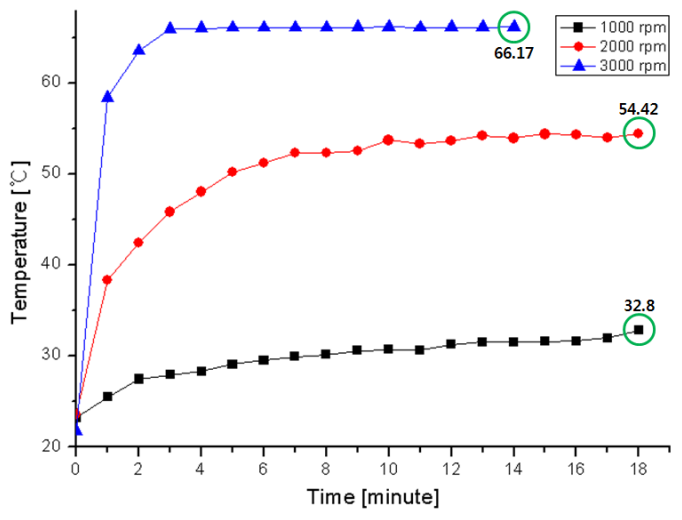

Fig. 11 Damaged under loading condition of B6304

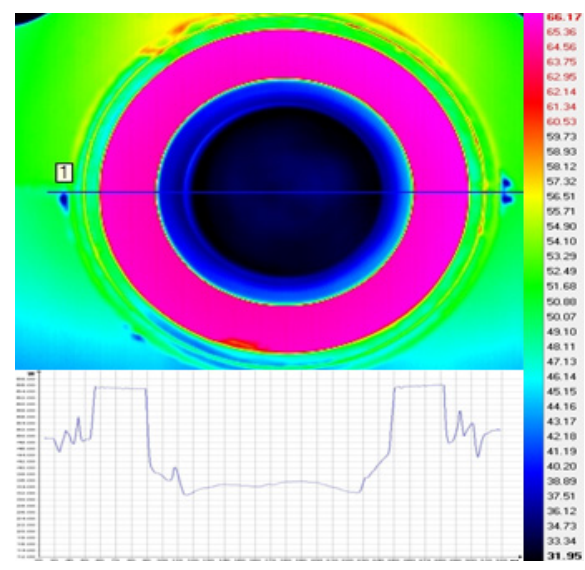

Fig. 12 Thermal image of damaged under loading condition in $3,000 \mathrm{rpm}$

$3,000 \mathrm{rpm}$. But when rpm became 2000, in case of damaged condition, the temperature increased by about $43 \%$. In case of damaged condition under loading, the temperature increased at about $66 \%$. This value rose to about $47 \%$ against normal condition. When rpm became 3,000 , the temperature of damaged condition under loading extremely increased at about $102 \%$. It rose to about $42 \%$ against normal condition.

One function of bearings as a power transmission element is to support load. Thus, mostly, the dynamic load is applied to the bearing. From this experimental consideration, it 
was confirmed that the infrared technique is very useful for the detection of the bearing damage by analyzing the temperature distribution through real-time monitoring.

\section{Conclusions}

In this paper, temperature characteristics according to the five-condition of bearing were analyzed through infrared thermography method. Damaged bearings by checking the following were easily detected: 1) The early temperature gradient, 2) The maximum temperature value according to each condition, 3) The rate of temperature increase according to $\mathrm{rpm}$. Based on these results, the non-contact, non-destructive abnormality diagnosis using the infrared thermography method will be useful for condition monitoring of rotating machine elements in the future.

\section{Acknowledgement}

This work was supported by the National Research of Korea (NRF) grant funded by the Korea government (MEST) (No. 2011-0026836)

\section{References}

[1] J. Lee and D. Han, "A study on the static and dynamic equivalent load of the ball bearings," Journal of the Korean Society of Automotive Engineers, Vol. 8, No. 1, pp. 157-162 (2000)

[2] D. Lim, Y. Cho and B. Yang, "Development of fault diagnosis system for ball bearings," Proceeding of the Korean Society for Power System Engineering, pp. 135-141 (1998)

[3] J. Woon, S. Kim, J. Yoo and J. Lee, "A study on the automatic diagnosis system of ball bearings for rotating machinery," Journal of the Korean Society of Mechanical Engineers, Vol. 19, No. 8, pp. 1787-1798 (1995)

[4] S. Lee, J. Kim and N. Kim, "Railway field application and case study using infrared techniques," Proceeding of the Fall Conference of the Korean Society for Railway, pp. 3320-3325 (2009)

[5] F. P. Incropera and D. P. DeWitt, "Fundamentals of Heat and Mass Transfer," 7th Ed., John Wiley \& Sons (2008) 